\title{
"Nós somos machistas": entrevistas com escritores/as brasileiros/as
}

\author{
Christian Grünnagel ${ }^{1}$ e Doris Wieser ${ }^{2}$
}

As entrevistas com escritores/as brasileiros/as reunidas neste dossiê $\hat{e}^{3}$ foram feitas durante a Feira do Livro de Frankfurt de 2013, que apresentou o Brasil como país convidado. Os estudos de gênero nos possibilitaram os instrumentos metodológicos para as primeiras questões em que nos focamos na percepção que têm esses(as) escritores(as) da posição do homem e da mulher tanto na sociedade brasileira em geral quanto nas suas obras em particular. Partimos do conceito de masculinidades (no plural) da reconhecida socióloga australiana R. W. Connell, 4 que mostrou - também através de entrevistas (com homens do seu país) - que uma concepção monolítica da masculinidade (e também da feminilidade) é demasiado simplista e não permite analisar as contradições internas dessas construções socioculturais. O título de seu trabalho mais influente, Masculinities (publicado em 1995), já indica a necessidade de pensar a masculinidade no plural. Nela, Connell distingue quatro "projetos" de masculinidade nas sociedades ocidentais: masculinidades hegemônicas, cúmplices, subordinadas e marginais (Connell, 2005, p. 76-81).

A masculinidade hegemônica representa o ideal atual de virilidade numa sociedade patriarcal concreta e constrói-se na máxima distância

\footnotetext{
${ }^{1}$ Doutor em letras românicas e professor do Instituto de Filologia Românica da Universidade de Giessen, Giessen, Alemanha. E-mail: christian.gruennagel@ romanistik.uni-giessen.de

2 Doutora em literatura ibero-americana e professora do Instituto de Filologia Românica da Universidade de Göttingen, Göttingen, Alemanha. Atualmente bolsista de pós-doutorado da Fundação Alexander von Humboldt na Universidade de Lisboa. E-mail: doris.wieser@phil.unigoettingen.de

${ }^{3}$ Agradecemos as transcrições a Francys de Andrade Pinheiro e Julieth dos Santos Cavalcanti, e as revisões dos textos a Augusto Rodrigues, Edvaldo Bergamo, Luciana Moreira Silva e Moizeis Sobreira. Um agradecimento especial a Verena Dolle, pelo apoio financeiro prestado, e a Manfred Prinz, pelo interesse que manifestou por este projeto, pela generosidade com que procurou transcritores e pelo apoio financeiro que proporcionou. Por último, mas não menos importante, agradecemos aos escritores e às escritoras pelo interesse e a participação neste projeto.

${ }^{4}$ Connell começou a publicar os seus escritos como homem (Robert), mas optou mais tarde por uma mudança de sexo e escolheu como novo nome Raewyn (veja-se a biografia no site oficial da socióloga, disponível em: <http://www.raewynconnell.net/p/about-raewyn_20.html>, acesso em: 20 jan. 2015), uma mudança frequentemente invisível nas publicações devido à abreviatura "R. W.”.
} 
da feminilidade, mas também da masculinidade subordinada, que Connell identifica principalmente nas masculinidades homossexuais. A masculinidade "cúmplice" tira partido das vantagens relacionadas com "ser homem" numa sociedade patriarcal, vantagens que Connell denomina "o dividendo patriarcal" (Connell, 2005, p. 79), embora não caracterize homens que se encaixem no ideal da masculinidade hegemônica. Essa masculinidade é "cúmplice" na medida em que tira proveito da estrutura patriarcal. Hegemonia e cumplicidade distinguemse nitidamente das masculinidades subordinadas porque a subordinação implica não participar do projeto hegemônico e das vantagens estruturais já mencionadas. Mais ainda, as premissas indispensáveis para poder encarnar a masculinidade hegemônica são duplas: não ser mulher e não ser gay. ${ }^{5} \mathrm{Tal}$ como implica o próprio termo "hegemonia", as sociedades patriarcais regem-se por uma hierarquia em que, por um lado, a masculinidade hegemônica se encontra no topo e a masculinidade cúmplice, muito próxima dela; e, por outro lado, a feminilidade e a masculinidade subordinada (frequentemente identificada com a feminilidade segundo o discurso heteronormativo e patriarcal) se encontram na base. Em contraste com esses três "projetos" de masculinidade (hegemonia, cumplicidade, subordinação), as masculinidades marginais se definem recorrendo abertamente a parâmetros socioeconômicos: sua marginalidade explica-se devido à sua condição precária em termos de pobreza, ou melhor, falta de capitais econômicos, culturais e simbólicos - segundo a terminologia de Pierre Bourdieu.

Em relação ao Brasil, pode-se falar de masculinidades marginais tanto no caso dos moradores pobres das favelas e periferias das grandes metrópoles como no de zonas rurais. Ambos são certamente também casos muito diferentes entre si. Trata-se de masculinidades "marginais" na medida em que os indivíduos não têm acesso ao projeto hegemônico, por mais que sejam "viris" ou "machistas", visto que a masculinidade hegemônica implica sempre poder econômico e simbólico: a hegemonia

\footnotetext{
${ }^{5}$ A questão é ainda um pouco mais complicada porque a masculinidade homossexual não representa o único exemplo de uma masculinidade subordinada segundo Connell. Todos os "projetos" masculinos, percebidos como "frágeis", "emocionais" ou que rompam de uma outra maneira com o ideal da masculinidade hegemônica ("sissy stuff", nas palavras de David e Brannon, 1976, p. 12), correm sempre o risco de serem relegados para a categoria da subordinação, independentemente da orientação sexual dos indivíduos (Connell, 2005, p. 79). Mas, como Connell vê a homossexualidade masculina como o exemplo mais importante e mais visível de uma masculinidade subordinada, oprimida pela hegemonia, concentramo-nos nela nas entrevistas seguintes.
} 
- termo que Connell (2005, p. 77) retoma de Antonio Gramsci - deixaria de sê-lo, se a maioria da sociedade não compactuasse com essa construção, ou, pelo menos, não concordasse com a masculinidade hegemónica como representante do ideal viril em vigor. Assim, esse ideal supõe a participação do indivíduo no poder da sociedade e, nesse sentido, inclui também parâmetros socioeconómicos na sua definição. A virilidade marginal, pelo contrário, está excluída do poder tanto político como económico e cultural.

É importante insistir que todas as masculinidades - com exceção das masculinidades subordinadas - tiram partido do patriarcado e situamse numa posição mais elevada no sentido social e simbólico em relação à feminilidade. Finalmente, para não cair na armadilha de considerar as masculinidades connellianas como traços rígidos de caráter, é indispensável sublinhar que Connell define todas elas como "projetos" que se realizam numa situação social concreta, quer dizer, elas não existem como "essências", mas sempre exigem práticas sociais para serem identificáveis. Por isso não há - sensu strictu - homens hegemônicos, cúmplices, subordinados ou marginais, mas somente masculinidades legíveis socioculturalmente como tais em situações sociais muito concretas. Isso implica também que um determinado homem na realidade pode assumir diferentes projetos de masculinidade dependendo do seu entorno e ambiente: pode encarnar, por exemplo, o projeto hegemônico no seu trabalho como gerente de uma empresa, atuar segundo o modelo "cúmplice" em casa com a esposa e os filhos e ter uma terceira faceta (subordinada e em tensão com o projeto hegemônico da sua vida profissional) no seu repertório quando tiver relações sexuais com o seu amante secreto.

Em nossa opinião, é importante salientar um último aspecto da teoria social da masculinidade de Connell, embora este não seja tão conhecido como a concepção das quatro masculinidades. Trata-se da sua insistência na complexidade das construções socioculturais do gênero e da importância do corpo e da sua materialidade nelas. Connell refuta tanto um "biologismo determinista", que vê apenas sexos e não quer tomar em conta o gênero, quanto posturas que ela denomina "pósestruturalistas", que veem somente práticas performativas e não aceitam que toda performance se baseia forçosamente num corpo concreto que oferece ou facilita algumas práticas, enquanto dificulta ou impossibilita outras (Connell, 2005, p. 49-59). Portanto, o gênero, 
segundo Connell, é uma construção sociocultural, mas que supõe sempre práticas que a autora define como body-reflexive (Connell, 2005, p. 61), quer dizer, práticas que têm como base um determinado corpo, mas que não significam nada em si sem um contexto sociocultural concreto e outros seres humanos que interpretam esse corpo e a sua performance seguindo as pautas socioculturais em vigor numa determinada sociedade.

Connell parte do seu trabalho sobre a Austrália para formular a teoria das masculinidades, mas esta assume, no entanto, uma leitura quase "universal", no capítulo "Masculinity politics on a world scale" (Connell, 2005, p. 260-266). Assim, ficamos tentados pela ideia de perguntar aos(às) autores(as) entrevistados(as) se percebiam também no Brasil atual fenômenos comparáveis às masculinidades analisadas pela socióloga australiana. É verdade que já existem vários trabalhos que evidenciam a existência das masculinidades connellianas na América Latina, mas são majoritariamente sociológicos. No que diz respeito aos estudos literários (e culturais) quase não há trabalhos na linha de Connell. ${ }^{6}$ Como o conceito de masculinidade(s) não se pode definir sem o de feminilidade(s), fizemos perguntas em torno da relação entre esses conceitos, mas também em torno de aspectos interdependentes destes, como a orientação sexual, a classe social ou a tradição patriarcal.

Antes de entrar nas entrevistas, parece-nos importante justificar o uso do termo "machismo" nas perguntas. Trata-se de um termo popular usado, por um lado, como clichê originado na Europa e nos Estados Unidos para designar (e denegrir) masculinidades sul-europeias e latinoamericanas e, por outro lado, também usado pelos próprios latinoamericanos para realçar a virilidade, fenômeno que se pode observar nas entrevistas aqui apresentadas, como o leitor poderá comprovar em seguida. No entanto, é importante saber que na sociologia, etnologia e antropologia da América Latina, o termo foi (e é) muito criticado por ser

\footnotetext{
${ }^{6}$ Para uma visão da masculinidade latino-americana como um fenômeno plural ("masculinidades"), ver Valdés e Olavarría (1998); Olavarría e Parrini (2000) - ambos os volumes reúnem estudos sobre vários países da América Latina; Archetti (2003) (Argentina); Fuller (2001) (Peru); Gutmann (2003) (América Latina); Gutmann (2007) (México); e, para uma tentativa de trabalhar sobre a lacuna mencionada nos estudos literários, ver Peluffo e Sánchez Prado (2010), volume dedicado à literatura latino-americana do século XIX; McKee Irwin (2003), sobre masculinidades mexicanas; Millington (2007), sobre a representação de masculinidades nas literaturas latino-americanas do século XX; e Grünnagel (2015), monografia que se dedica ao estudo de masculinidades em crise nas literaturas de vários países latino-americanos (Argentina, Brasil, Uruguai e Peru), de 1967 a 2007.
} 
considerado simplista, generalista e estereotipado. ${ }^{7}$ Apesar dessa crítica, optamos por usar os termos "machismo" e "machista" nas entrevistas para designar provisoriamente um aspeto da masculinidade hegemônica, "cúmplice" (também subordinada e marginal?) e para averiguar se autores(as) brasileiros(as) atuais continuam entendendo o termo como adequado para a interpretação da sua própria sociedade ou se a crítica acadêmica já se perfilou no pensamento dos(as) intelectuais entrevistados(as). Na verdade, as entrevistas revelam que o conceito é usado na sua acepção popular, como se pode verificar nas respostas.

Vale ainda a pena destacar, no que diz respeito à pergunta acerca do lugar social que ocupam práticas "machistas", que os(as) autores(as) entrevistados(as) dividiram-se, para nossa surpresa, em dois grupos opostos. Embora alguns defendam que um comportamento "machista" depende de uma falta de cultura e educação e que, por isso, o machismo continua sendo problemático especialmente entre masculinidades marginais, perdendo força nas classes média e alta; outros sublinham a presença e continuidade de práticas machistas em todas as classes da sociedade brasileira atual, com a única - mas importante - diferença de que o machismo é bem visível e "evidente" nas classes baixas, enquanto nas classes médias e altas está mais camuflado e reduzido à intimidade do casal. A coexistência dessas duas posições poderá ter sido resultado do fato de os(as) entrevistados(as) estarem perante estrangeiros e sentirem uma maior necessidade de explicar a sociedade brasileira, dando conta, ao mesmo tempo, de algumas das tensões entre diferentes setores da sua sociedade.

Finalmente, também no que diz respeito à homossexualidade, categoria igualmente analisada por Connell, é visível uma discrepância entre as posições dos(as) nossos(as) interlocutores(as). Praticamente todos(as) afirmam que, apesar das grandes marchas de orgulho LGBT em cidades como São Paulo ou Rio de Janeiro e do aumento de personagens gays em telenovelas, continua sendo muito difícil que uma pessoa assuma a sua homossexualidade, tanto no seio da família como na vida pública. Não obstante, a posição dos(as) escritores(as) frente à demonstração de afeto entre casais do mesmo sexo e à luta dos grupos LGBT pelos seus plenos direitos cívicos varia. Enquanto a maioria

${ }^{7}$ Ver, por exemplo, Mirandé (1997, p. 16-18 e p. 65-79); Ramírez (1999, p. 16-35) e Gutmann (2007, p. 24-27 e p. 221-242). 
mostra empatia, apoia essas lutas e constata a necessidade de criar uma maior aceitação através da educação e da visibilização, também encontramos posições mais neutras ou mesmo conservadoras, que passam pela recusa.

Talvez seja pertinente, por último, dizer umas palavras sobre a escolha dos(as) nossos(as) interlocutores(as). Na Feira do Livro de Frankfurt de 2013 estiveram presentes aproximadamente 70 autores brasileiros. O nosso objetivo foi entrevistar, por um lado, escritores(as) de diferentes classes sociais, diferentes regiões, diferentes sexo e orientação sexual, para abrir um leque o mais amplo possível em relação à teoria connelliana aqui descrita. Por outro lado, escolhemos autores cuja obra nos interessa particularmente como leitores(as) e acadêmicos(as). Por essa razão, seguem-se questões que dizem respeito à obra de cada um em particular, dando o maior realce possível às suas preocupações centrais, em termos formais e estéticos, mas também em termos de conteúdo, principalmente no que se refere aos diversos tipos de violência presentes em sua literatura. Sempre que nos pareceu relevante, fizemos também perguntas sobre as conexões e contrastes entre as obras dos(as) entrevistados(as).

\section{Referências}

ARCHETTI, Eduardo P. (2003). Masculinidades: fútbol, tango y polo en la Argentina. Buenos Aires: Antropofagia.

CONNELL, R. W. (2005). Masculinities. 2. ed. Berkeley; Los Angeles: University of California Press.

DAVID, Deborah S.; BRANNON, Robert (1976). The male sex role: our culture's blueprint of Manhood, and What it's Done for Us Lately. In: (Eds.). The forty-nine percent majority: the male sex role. Reading: Addison-Wesley.

FULLER, Norma (2001). Masculinidades: cambios y permanencias. Varones de Cuzco, Iquitos y Lima. Lima: Fondo Editorial de la Pontificia Universidad Católica del Perú.

GRÜNNAGEL, Christian (2015). Von Kastraten, Hermaphroditen und anderen Grenzgängern lateinamerikanischer Männlichkeit in Literatur und Film (1967-2007): Ein Blick der 'Peripherie' auf Sex und Gender. (No prelo.) 
GUTMANN, Matthew C. (Org.) (2003). Changing men and masculinities in Latin America. Durham; London: Duke UP.

GUTMANN, Matthew C. (2007). The meanings of macho: being a man in Mexico City. 2. ed. Berkeley; Los Angeles; London: University of California Press.

MCKEE IRWIN, Robert (2003). Mexican masculinities. Minneapolis: University of Minnesota Press.

MILLINGTON, Mark (2007). Hombres in/visibles: la representación de la masculinidad en la ficción latinoamericana (1920-1980). Bogotá: Fondo de Cultura Económica.

MIRANDÉ, Alfredo (1997). Hombres y machos: masculinity and Latino culture. Oxford: Westview Press.

OLAVARRÍA, José; PARRINI, Rodrigo (2000). Masculinidad/es: identidad, sexualidad y familia. Santiago de Chile: FLACSO.

PELUFFO, Ana; SÁNCHEZ PRADO, Ignacio A. (2010) (Org.). Entre hombres: masculinidades del siglo XIX en América Latina. Madrid: Iberoamericana; Frankfurt: Vervuert.

RAMÍREZ, Rafael L. (1999). Dime capitán: reflexiones sobre la masculinidad. 2. ed. Río Piedras: Huracán.

VALDÉS, Teresa; OLAVARRÍA, José (1998) (Org.). Masculinidades y equidad de género en América Latina. Santiago de Chile: FLACSO.

Recebido em agosto de 2014.

Aprovado em dezembro de 2014.

\section{resumo/abstract}

\section{“Nós somos machistas": entrevistas com escritores/as brasileiros/as}

Christian Grünnagel, Doris Wieser

Este dossiê reúne seis conversas com escritores(as) brasileiros(as) levadas a cabo no âmbito da Feira do Livro de Frankfurt em 2013: Ana Paula Maia, Beatriz Bracher, Bernardo Ajzenberg, Carola Saavedra, Ferréz, Luiz Ruffato e Marcelino Freire. As primeiras questões das entrevistas centram-se em assuntos relacionados com os estudos de gênero, nomeadamente os diferentes conceitos de masculinidade(s) e feminilidade(s) na sociedade e na literatura brasileiras, partindo da teoria elaborada pela socióloga australiana R. W. Connell, uma das 
mais relevantes acadêmicas contemporâneas na área das masculinidades e das relações de gênero. Segue-se uma série de perguntas sobre as particularidades da obra de cada um(a) dos(as) escritores(as), as suas principais preocupações estéticas e as conexões com as obras dos(as) outros(as).

Palavras-chave: masculinidades, feminilidades, entrevistas, literatura brasileira contemporânea.

\section{"We are machistas": Interviews with Brazilian Writers}

\section{Christian Grünnagel, Doris Wieser}

This dossier brings together seven interviews carried out at the Frankfurt Book Fair in 2013 with the following Brazilian writers: Ana Paula Maia, Beatriz Bracher, Bernardo Ajzenberg, Carola Saavedra, Ferréz, Luiz Ruffato and Marcelino Freire. The first part of each interview focusses on gender issues, in particular on diverging concepts of masculinity and femininity in Brazilian society and literature. These concepts are based on the theory developed by the Australian sociologist R. W. Connell, who is one of the most distinguished contemporary scholars of masculinities and gender relations. The second part shifts its focus to question about the particularities of each writer's work, their main aesthetic concerns and the connections between their works.

Palavras-chave: masculinity, femininity, interviews, contemporary Brazilian literature. 